\title{
Dramatic Structure in Al- Huttai'a's "Al-Karm"
}

\author{
Myson Karim Ibrahim Alqudah \\ Arabic Department \\ Mutah University \\ Jordan
}

\begin{abstract}
This study sets out to present a socio-dramatic story outlining the dramatic elements; namely setting, action, climax, conflict, dialogue, epiphany, denouement and the ending, all of which form the complex target of the poem represented in presenting a full-fledged story regardless of the lyrical nature of the poem. With view at highlighting the aesthetics of the text, the study aims at exploring its dramatic structure, the action, the poem's dynamics, the personification involved, the extent of objectivity, the dramatic language and the narrative technique.
\end{abstract}

Keywords: Pre-Islamic Poetry, Dramatic Poetry

\section{Introduction}

Drama is "a Greek word indicating the source of a certain action or event or performance" (164).Thus, it simply means: the action. Etymologically speaking, "Drama" originates from the Greek " Dar Menon" indicating " performing an action on stage or within life's ups and downs" (23). Hence, the term "Drama" has been given to "a form of literary work presented to be staged by performers before an audience; it typically draws on the form of the epic or the short story or the poem as long as it explores an action, or the lyrical ballad as long as it represents emotional expression" (11).

Cleanth Brooks and Robert Penn Warren state that Each poem is based on a certain motive, where the poem is the representation of this motive; in other words, it is a response to a certain state, so it is a mini-drama, or sometimes a full-fledged one. (38-49). This shows that drama is integrated in each poem regardless of the extent to which it is manifested to the reader. Essentially, there is no one-to-one correspondence between the experience and the dramatic elements. In other words, drama is not restricted to approaching the poem and deeming it dramatic; neither is it part and parcel nor a characteristic of its nature. An experience cannot be deemed dramatic unless it reflects the feelings and thoughts of the poet and his methodology of attaching himself to the experience and the degree of his involvement in it and expressing this involvement. After all, it is the poet who decides the degree of the dramatic or lyrical nature of the poem, and he is the one who endows it with the concrete form that maintains its peculiarity and effectiveness.

\section{Discussion}

" Al-Karm" by Al Huttai'apresents a comprehensive story-linein an excitingly literary method, which made it part of the Arab poetic canon. In terms of its content, it focuses on a number of subtopics as follows

First Subtopic: Description of the nomads, their children and the desert Tying his belly, he is starving for three days in the deserted Tayha' His toughness views company gloominess and seclusion a blessing In its corners he left a poor wife along three poor children like lambs Barefoot and naked, never tasted bread nor wheat since birth (133-134).

Second Subtopic: The guest and the father-son dialogue Viewing a shadow, he got scared recognizing him a guest, he got burdened Foodless, he prayed so that the guest will not be deprived of meat Viewing his father's dilemma the son asked to slaughter him for food Fearing the guest would report them tribes and stigmatize them He thought, then refrained, ultimately he embarked on the slaughter (ibd)

Third Subtopic: Zebra Hunting Suddenly Zebras showed up systematically following their leader Them approaching water he followed targeting them not water Waiting till they quenched their thirsthe targeted them with an arrow A fat female zebra collapsed which was full of flesh and fat (ibid) 
Fourth Subtopic: Happiness of the nomad's family for achieving hospitality So delighted while dragging it and seeing it bleeding They retained their calmness as they maintained their reputation, And the father became the father of the guest, and so did the mother (ibid)

These subtopics represent a sound narrative technique of storytelling, as they present a poetic story through which the poet managed to excitingly express his thoughts including the major narrative elements of time, place, characters, climax, and denouement. In addition, the poem touches on dramatic elements as it involves polyphonic discourse and multiple actions and movements within overlapping timeframes.

In the first subtopic, the poet established a dramatically narrative atmosphere outlining the place ( Tayha') and highlighting its desolation as it lacks all requirements of existence and all traces of previous life such as paintings as remnants of earlier dwellers. The place is significantly seminal to fiction as it provides the space where characters move and involve in dramatic actions.

As the protagonist is aware of the poor conditions and resources of the place has limited his options within the harsh environment. Thus he resorted to patience, which has made him and his family give up to hunger and the threat of impending death. This is textually reflected in the words (tying, starving) representing the lack of will and the complete submission to the desolate and dismal conditions. This has made it almost impossible for the protagonist to interact with this place, thus he had no option but endurance, tying the belly and dexterously using his hunting skills. Thus, the place represents the suffering, thoughts and vision of the protagonist and ignites imagery in the recipient, which helps him forms a full picture of it.

The poet then goes on to describe the characters. For the pivotal character (the protagonist), the poet employs concert elements of description such as poverty, hunger, in addition to the psychological sketch such as loneliness, dejection and misery. Moving to the other characters who contribute to the plot, the poet deployed three sons of the protagonist, who are equally melancholic. They are barefoot, starving and can hardly procure food. That is why they are described as lambs, signifying their misery and poverty. The poet also dwells on binary oppositions (172)such as (company-abandoned) and seclusion-blessing), which contribute to the shock and disillusionment on the part of the reader as it is taken for granted that the company necessarily means belonging, and seclusion is a curse, not a blessing. Evidently, such employment of binary oppositions represent a technique that aims at drawing readers; attention to defying common norms; i.e deviation (81).

Notwithstanding the fact that such binary oppositions used in the first subtopic apparently connote an atmosphere of discord, they ultimately synthesize to denote a unified vision reflecting internal conflict and deep anxiety, confusion and psychological suffering resulting from the desert harsh environment. As such, the binary opposition technique reflects the gap or " anxiety level"(57)which contributes to creating the poetic nature; the more the poetic nature, the more the absolute binaries, which in turn contribute to the poetic nature of the text. (109).

A critical look at the second subtopic shows that the abundance of verb forms makes the reader reconsider the recurrent nominal forms in the first subtopic. There are around 19 nominal forms in the first subtopic(verses 1-4); such as(starving, three, tying, belly, deserted, Tayha', deserted, he, gloominess, company, seclusion, toughness, blessing, corners, wife, along, three, children, lambs). The nominal forms reflect the stable atmosphere of starvation and deprivation as well as the deep anxiety of the protagonist as "the nominal clause essentially reflects stability of the situation as the name denotes stability of the signified without any internal or external renewal" (99).

As far as the second subtopic is subtopiced, the poet employed around 14 verbal forms, namely ( viewing, scared, recognizing, got, burdened, prayed, asked, slaughter, fearing, report, stigmatize, thought, refrained, embarked). In contrast to the employment of the nominal forms, this employment of the verb forms connotes significant fluctuations of the situations because "the aim of employing verbs in the sentence is to show renewal of events and their gradual occurrence." (100).

Further comparison between the two mentioned subtopics yields significant statistical notes that contribute to elucidating the dramatic description and the psychological action. For example, in the description scene, the ratio of the nominal forms to the verb ones is $4: 2$, which means that the descriptive dynamics is higher than the kinetic one. This is so common on the shorty story narrative technique, where the author prefers the extensive use of nominal structure, especially in the case of psychological narratives. 
In the third subtopic, the poet managed to create a great sense of disillusionment on the side of the protagonist as well as the reader at the same time. This is represented in shifting the focus from the debilitating conditions to a totally different reality starting with (Suddenly Zebras showed up....).

This event formed a noticeable transition promising a solution as he surprisingly introduced the group of Zebras; such disillusionment is a significant technique; " the significance of each stylistic tool is directly proportional the degree of shock, the more it is unexpected, the more its effect on the reader" (86).

Another manifestation of conflict shows up in this subtopic, represented in the conflict between paternities, which makes the father refrain from slaughtering his son, and hospitality, which as non-negotiable Arab value. The reader witnesses the fluctuations in feelings, hesitation and anxiety on the side of the protagonist as he is considering his son's offer, a state that became displaced on the reader himself. Suddenly, a supernatural solution is looming, free from the intervention of man, represented by the appearance of zebras.

In this cinematic scene, the poet projects the parallel between the protagonist's desire and that of the zebras in addition to its collapse. The parallel is shown as the zebras are very thirsty ( for water), and the protagonist is very thirsty as well ( for the zebras' blood !). Them the poet shows the moment of hunting encapsulated within the anxiety of the protagonist as he is waiting them to finish drinking water, where he targeted one with an arrow, and happily dragged the dead zebra.

It is worth noting the poet ends his poem happily, compared with the melancholic beginning, thus representing the dramatic sequence of events and the gradual change from the negative to the positive. In other words, the whole family, which has been suffering from poverty and misery so much so that they could not manage the food for the guest, is now a prosperous one.

On the other hand, the subtopic witnesses some exaggeration in the sudden collapse of the zebra, which reflects the deep need to stop starvation and satisfy the guest. This is supported by the fact that the hunter is skillful who would never give the zebras a chance to escape. This is a deviation from the common norm in pre-Islamic poetry, where the poets would show zebras enjoying water without any disturbance from hunters, who, if suddenly want to hunt would surely miss the target as zebras are not for food but for ornament (83).

\section{Action and the Poem Kinetics}

The action is considered one of the major pillars of drama; not the regular action that lacks tension and conflict, but the dramatic one that riffles with kinetics and tension delivered to the reader ripe (121). That is why the action in the poem is not narrated, but dramatized, which helps the reader imagine, which all add to the kinetic and dramatic nature of the poem.

For example, in the third and fourth subtopics, the poet employed verbs that signify the kinetic nature of the poem. For example, the verb (followed) is used to reflect quiet and unrecognizable movement so that the zebras do not flee. Similarly, ( waiting) represent his tension in waiting until they quench their thirst to throw his arrows, and the verb ( targeted) represents a kinetic imagery showing strength and seriousness on the part of the hunter.

It should be noted that such word choice and langue use indicate the intention of the poet in using language that reflects what he is thinking of as well as his personal view of things, aiming at attracting the reader to his peculiar world, thus showing that the text aesthetics influences the reader and forms one of the three elements of the stylistic analysis (linguistic, objective-oriented and esthetic) (15).

\section{Personification and Objectivity}

One of the major characteristics of dramatic discourse is that it is quite objective regardless of the subjective experience. Dramatic discourse does not isolate the self from the surrounding, but creates a dialectical relationship between them. In other words, drama manages to commodity the self and presents the topic in a rather abstract manner so that it becomes more transparent. This is because drama is not concerned with the theme and meaning as much as the surrounding realities creating life. So, the poetic outlook to drama is essentially an outlook to and trough things; it is concrete, not abstract. (280-81). As objectivity is seminal to drama, it follows that not only does the poet have to have an objective methodology, but he also has to take care of details. This is because the mere observations of life yield a traditional narrative, not necessarily a dramatic one. In this regard, it is vital to refer to the intertextual aspect of the poem as the intention to slaughter the child links to the story of AbrahamIsmail. 
This link with the Quranis significant as " referring to the past is one of the effective means of creativity as it creates a kind of dialogue between the present text and the absent past, thus leading to interacted and multifarious forms of creativity (43).

The intersexuality employed, however, highlights the contrast between the major characters in the two stories. Whereas Abraham was so calm and confident as a prophet receiving revelation which he had to obey for his benefit, the protagonist in the poem is full of anguish as he has been in conflict for ages along with his starving family. In addition, in the Abrahamic story, the sacrifice is a lamb, while in the poem it is a zebra.

\section{Dramatic Language}

Evidently, drama seeks to portray rather than narrate. Hence, its language is rather graphic than affirmative. In other words, it avoids affirmation and explicitly and adopts allusion and implicitly. As critic Dawson states, dramatic language is " the language that does not describe, but rather present or represent; in other words, it becomes the topic it seeks to highlight as it seems to come direct from the speaker" (26).This links with Luigi Pirandello's view that action speaks better than words, which makes drama "an essentially creative language; the more the recipient's understanding, the more the dramatic response; hence the dramatic touch" (28).

Looking at the poem, the reader finds that the major character is intrinsically connected to the subtopics of the poem in addition to the elements of time, place, climax and denouement, which the poet skillfully expressed in a poetic language that targets the ultimate meaning of the text; and ultimately contributing to creating the mosaic of the dramatic language of the poem. On the other hand, the type of metric line adopted for the poem gives the poet ample space to express his feelings using the suitable rhyme scheme, which in turn further helps in expressing his agonies.

\section{Conclusion: Narrative Technique}

The narrative technique of the poem is essentially a dramatic one. In fact, some parts of the poem may be employed in both internal and external dialogues, which all helps in further dramatizing characters in the poem (28). The point is not simply to create an attractive and important story, but rather to skillfully endow the work with implicit rather than explicit meaning, in addition to the dexterous use of dramatic elements of characters, action, and conflict. (300-305).

As such, the story managed to enunciate the inner reality of the poet in an objective method. It also endowed the story with more dramatic nature creating more suspense and follow up. That is why the poem is full of aesthetics and imagery taken from local environment as well as cultural repertoire.

For example, the poem starts with the image of the father tying his belly from starvation, which is a major tradition among nomads. In addition, there is the scene of the walking family like lambs to signify their starvation and the scene of the father being in conflict between slaughtering his son and depriving his guest of food, which shows the Quran as a source of the poet's knowledge as mentioned above. Finally, there is the dexterous portrayal of the father anxiously waiting for the zebras to drink and then hunt one of them; a scene that is full of vitality without any affirmative elements.

\section{References}

Abu Al Rida, Saad (1988). On Structure and semiotics. AL Maarif Property, Alexandria.

Abu Deeb, Kamal, (1987). On poetics. Arab Research Foundation Publishers, Beirut.

Kattos, Bassam, (199)2. "Aspects of stylistic deviation in the works of Bardooni". Dirasat. 19 (1) - (109).

Al Alaq, A. Jafar, (nd). Dramatic structure in modern poetry: " The War" A Case Study. 7 (1-2).

AL Huttai'a, (2005). The complete works. ED. Hamdo Tammas. AL Marifa Publishers, 2nd ed. (133-134).

Al Khayyat, Jalal, (1982). Dramatic origins in Arabic poetry. Al Rashid Publishers, Ministry of Culture and Media- Iraq.

AL Musdi, Abdel Salam, (1993). Stylistics and style. Saad Publishers, Kuwait.

Ayyad, Shukri, 1988. Language and creativity: Principles in Arabic aesthetics. International Press, Cairo.

Al Zanad, Al Azhar, (1992). Studies in Arabic rhetoric. Arab Cultural Center Publishers, Beirut.

Dousin, C.W, (1981). "Drama and the dramatic."Critical Concept Encyclopedia. Trans. Abdelwahid Lu'lu'a, Al Rashid Publishers- Baghdad.

The Holy Quran, AL- Safat.

Ismail, Izzedin (1972). Technical and semantic issues and aspects of contemporary Arabic poetry. Beirut.

Kafaj, et.al (1992). Stylistics and Arabic Rhetoric, 1st ed. Egypt-Lebanon Publishers - Cairo.

Kulaib, Saad Eddin (1997). Modernism awareness. Arab Writers Society, Damascus.

Nasrat, Abdel Rahman (1982). Imaegry in pre-Islamic Poetry in light of modern criticism. Al Aqsa Library, Amman-Jordan.

Rahoma, Mohammad (1993). The circle and the way out: A study in the works of Al Bardooni. Al Shyyab Libraty, Al Mina.

Sarhan, Samir, nd. Studies in dramatic literature. Cutlrual and Media Affairs Publishers, Baghdad. 